\title{
Preliminary Study of Buffer Ratio in Protein Extraction from Placental Cotyledons of Kedah-Kelantan Cattle
}

\author{
Y. Y. Tee ${ }^{a}$, K. Mat ${ }^{a, b, *}$, M. A. Adam ${ }^{a}$, N. D. Ruslia,b, C. H. Hasnita ${ }^{a, b}$, \& H. N. Mohd Khalid ${ }^{a}$ \\ ${ }^{a}$ Faculty of Agro-Based Industry, Universiti Malaysia Kelantan, \\ Locked Bag No. 100, 17600 Jeli, Kelantan, Malaysia \\ 'Institute of Food Security and Sustainable Agriculture, Universiti Malaysia Kelantan Jeli Campus, \\ Locked Bag 100, 17600 Jeli, Kelantan, Malaysia \\ *Corresponding author: khairiyah@umk.edu.my \\ (Received 11-09-2019; Revised 04-06-2020; Accepted 17-06-2020)
}

\begin{abstract}
Protein extraction is a preliminary step of protein purification which mainly focus on maximization of total protein yield. The heterogeneous properties cause diversification of protein; therefore, there is no absolute protocol in protein extraction. The ratio of buffer gives different protein concentrations in different types of mammalian tissues, and this condition leads to the study of optimization of buffer ratio to obtain a better total protein yield. The objectives of this study were to compare the total protein yield based on three different ratios of buffer used. The phosphate buffer saline (PBS), radioimmunoprecipitation assay (RIPA) buffer, and RIPA buffer with the addition of protease inhibitor (Pi) were used with the ratios of 1:1, 1:3, and 1:5. Fetal cotyledons removed from the placenta have undergone mechanical disruption, incubation, sonication, and centrifugation. The supernatant was retained and quantified with Bradford assay to determine the total protein yield based on the standard curve of bovine serum albumin (BSA). There was a statistically significant different between buffer ratio $(p<0.5)$ in RIPA and RIPA with addition of protease inhibitor buffers. RIPA buffer with the ration of 1:1 gave the best total protein yield $(194.880 \pm 15.089 \mathrm{mg} / \mathrm{g})$. As a conclusion, there was a significant interaction between buffer types and have greatly enhanced the total protein yield obtained from placental cotyledons of Kedah-Kelantan cattle.
\end{abstract}

\section{Keywords: fetal cotyledon; placenta protein extraction; Pregnancy-Specific Protein B (PSPB); total protein yield}

\section{INTRODUCTION}

The proteomic study particularly in pregnancyrelated proteins has become interest to some researchers whose intentions not only targeted to human, but also act as an important tool in improving the livestock production (Romano \& Larson, 2010; Friedrich \& Holtz, 2010). The study of placental protein helps determine the function of specific protein in regulating the pregnancy. Pregnancy-associated glycoprotein (PAG) is produced by binucleate cells of the trophectoderm of ruminants (Touzard et al., 2013) and it can be detected started from the third week of pregnancy until parturition in the serum of pregnant cows (Abdulkareem, et al., 2010; Wallace, et al., 2015). The PAG can be detected during the third weeks of pregnancy until parturition in the serum of pregnant cows and this makes it a potential pregnancy marker tool that may help improve the breeding system in ruminant livestock industry (Piechotta et al., 2011; Wallace et al., 2015; Chaves et al., 2017).

The preliminary step of protein purification is aimed at concentration of the protein sample which in term of processing volume and increase the portion of target protein in total protein. However, due to the diversity of protein in term of structures and properties and is heterogeneous, there is no exact extraction method that able to produce a similar result in different types of protein. Hence, the function and mechanism of specific protein in regulating the pregnancy and the main problem leading to pregnancy disorder can be identified. Therefore, the protein extraction is one of the key factors in ensuring the succeed of the proteomic study by maximizing the total protein yield extracted from culture cells or tissues. Few factors must be taken into consideration prior to maximizing the crude protein yield as the protein is a very sensitive to the high fluctuations of temperature, $\mathrm{pH}$, and the presence of protease as well as the location of targeted protein in the tissue.

The presence of buffer is very important since the change of $\mathrm{pH}$ can affect the protein structure and the changes in the force of attraction between the groups of side chains of the protein could lead to the unfold and dysfunction of the protein. Different types of buffer were used in the protein extraction of PAG in some researches such as potassium phosphate buffer, PBS 
and Tris- $\mathrm{HCl}$ buffer with different ratios (Majewska et al., 2011; Barbato et al., 2013; Zhao et al., 2014). Hence, the objectives of this study were to compare the yield of protein concentrations from fetal cotyledon of the bovine placenta using different types of buffer and to optimize the ratio of the buffer used in the protein extraction process.

\section{MATERIALS AND METHODS}

\section{Collection of Placental Cotyledons}

The placenta was collected from post-parturition cattle Kedah Kelantan in Agropark, University Malaysia Kelantan Jeli Campus. The fetal cotyledons were removed from the placenta and stored at $-20^{\circ} \mathrm{C}$ until use (Bériot et al., 2014).

\section{Preparation of Buffer Solution and Ratios}

Phosphate buffer saline $(130 \mathrm{mM} \mathrm{NaCl}+2 \mathrm{mM} \mathrm{KCl}$ + $10 \mathrm{mM} \mathrm{Na}_{2} \mathrm{HPO}_{4}+1 \mathrm{mM} \mathrm{KH} \mathrm{PO}_{4}+1 \mathrm{M} \mathrm{HCl}, \mathrm{pH}$ 7.6) and radioimmunoprecipitation assay (RIPA) buffer (150 $\mathrm{mM} \mathrm{NaCl}+5 \mathrm{mM}$ EDTA $+15 \mathrm{mM}$ Triton X-100 + $3 \mathrm{mM}$ $\mathrm{SDS}+24 \mathrm{mM}$ sodium deoxycholate $+5 \mathrm{mM} \mathrm{HCl}$ ) were prepared. The volumes of both buffers needed in each extraction process were prepared based on the ratio of tissue to buffer (w:v) i.e., 1:1, 1:3, and 1:5, respectively as shown in Table 1 . The volume of RIPA buffer with the addition of protease inhibitor $(\mathrm{Pi})$ were prepared as presented in Table 2.

\section{Protein Extraction}

The fetal cotyledons were cut into $2 \mathrm{~cm}^{2}$ size, and $1 \mathrm{~g}$ of tissue was weighed and transferred into the prechilled mortar followed by the addition of PBS based on the ratio. The sample was ground until fully dissolved and incubated for 2 hours under $4^{\circ} \mathrm{C}$. The same procedure was repeated on RIPA buffer and RIPA+Pi buffer but with only 30 minutes incubation time for RIPA+Pi due to the short lifespan of $\mathrm{Pi}$. The samples were sonicated with the amplitude of $30 \%$ and 3 seconds of pulse on and off for three minutes. The samples were then

Table 1. The volume of buffer and tissue weight based on the ratios

\begin{tabular}{ccc}
\hline Ratio (w:v) & Sample weight $(\mathrm{g})$ & Volume of buffer $(\mathrm{mL})$ \\
\hline $1: 1$ & 1 & 1 \\
$1: 3$ & 1 & 3 \\
$1: 5$ & 1 & 5 \\
\hline
\end{tabular}

Table 2. Volume of radioimmunoprecipitation assay (RIPA) buffer and protease inhibitor based on the ratios

\begin{tabular}{cccc}
\hline Ratio (w:v) & $\begin{array}{c}\text { Sample } \\
\text { weight }(\mathrm{g})\end{array}$ & $\begin{array}{c}\text { Volume of } \\
\text { buffer }(\mu \mathrm{L})\end{array}$ & $\begin{array}{c}\text { Volume of protease } \\
\text { inhibitor }(\mu \mathrm{L})\end{array}$ \\
\hline $1: 1$ & 1 & 990 & 10 \\
$1: 3$ & 1 & 2970 & 30 \\
$1: 5$ & 1 & 4950 & 50 \\
\hline
\end{tabular}

centrifuged at $4^{\circ} \mathrm{C}, 12,000 \mathrm{rpm}$ for 1 hour, and the supernatant was retained and quantified with Bradford assay.

\section{Bradford Assay: BSA Standard Calibration Graph}

Bovine serum albumin (BSA) master stock was prepared by the addition of $0.5 \mathrm{~g}$ into $2 \mathrm{~mL}$ of deionized water to produce $250 \mathrm{mg} / \mathrm{mL}$ of BSA concentration. Two $\mu \mathrm{L}$ was taken out from the master stock and added into $500 \mu \mathrm{L}$ of $0.1 \mathrm{M}$ phosphate buffer to produce BSA with a concentration of $1 \mathrm{mg} / \mathrm{mL}$ and labelled as tube 1. Phosphate buffer at the volume of $250 \mu \mathrm{L}$ was added into each of 6 microcentrifuge tubes labelled with tube 2 to 7 . Two folds dilution by transferring $250 \mu \mathrm{L}$ into tube 2 , mixed well, and the same amount was transferred to tube 3. The same steps were repeated to the subsequent tubes. Table 3 represented the BSA concentration in each tube. Eight test tubes containing $1 \mathrm{~mL}$ of Bradford reagent were prepared with label "blank" and tubes 1 to 7. Phosphate buffer at the volume of $100 \mu \mathrm{L}$ was added into "blank" tube and mixed well. BSA at the volume of $100 \mu \mathrm{L}$ was transferred from microcentrifuge tube 1 into the test tube labelled with the same number and mixed well, and the same step was applied to the subsequent tubes, and left for 10 minutes. The mixtures were separately transferred into $1 \mathrm{~mL}$ cuvette. The absorbance reading was taken from spectrophotometer (Thermo Scientific Gynesis 20, USA) with a wavelength of $595 \mathrm{~nm}$ in chemistry laboratory. The test was replicated three times and plotted into a graph to obtain the equation $(y=m x+c)$ and $R$ square value $\left(R^{2}\right)$.

\section{Quantification of Protein Concentration}

The optimization of unknown protein amount was carried out to identify the suitable dilution factor of unknown protein sample in Bradford assay. Bradford assay was carried out on each dilution factor and the absorbance value of each sample was recorded and determined whether the value falls within the range of absorbance value in BSA standard calibration graph (Figure 1). Two hundred times (200x) dilution factor was chosen to identify the sample's protein concentration in Bradford assay. The data collected were analyzed by using statistical package for the social sciences (SPSS) version 20. One-way and two-way analysis of variance (ANOVA) were conducted at 95\% confidence level.

\section{RESULTS}

\section{Buffer Type}

The results of protein concentrations for the buffer ratios of 1:1, 1:3, and 1:5 in PBS, RIPA, and RIPA+Pi buf-

Table 3. Bovine serum albumin (BSA) concentration from 1000 to $16.125 \mu \mathrm{g} / \mathrm{mL}$ by 2-fold dilution

\begin{tabular}{lccccccc}
\hline \multicolumn{1}{c}{ Tube } & 1 & 2 & 3 & 4 & 5 & 6 & 7 \\
\hline $\begin{array}{l}\text { Protein } \\
\begin{array}{l}\text { concentration } \\
(\mu \mathrm{g} / \mathrm{mL})\end{array}\end{array}$ & 1000 & 500 & 250 & 125 & 62.5 & 31.25 & 16.125 \\
\hline
\end{tabular}




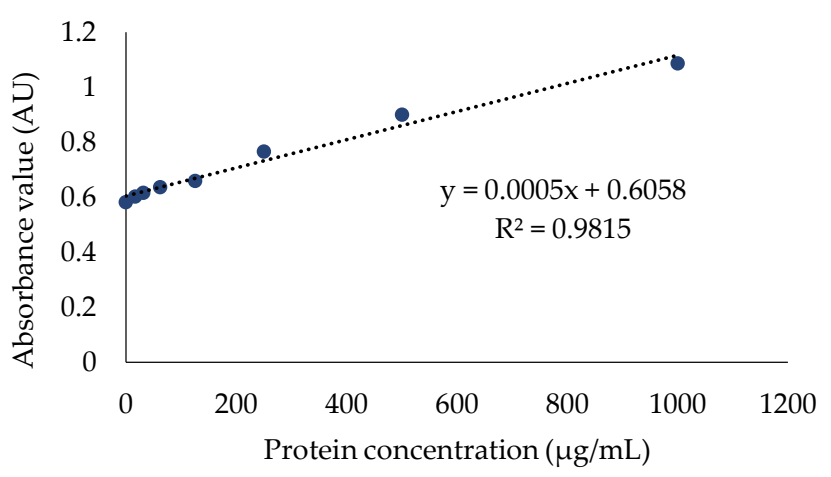

Figure 1. Standard calibration graph for bovine serum albumin (BSA) protein standard with Bradford assay

fers are presented in Figure 2. There was a statistically significant difference in protein concentrations between buffer ratios $(p<0.5)$ in RIPA and RIPA+Pi buffers. However, there was no significant difference in protein concentrations between buffer ratios in PBS buffer. The highest protein concentration $(\mathrm{mg} / \mathrm{g})$ in RIPA buffer was found in the buffer ratio of 1:1 $\left(194.880 \pm 15.089^{p}\right)$ that was significantly higher $(p<0.05)$ compared to those in the buffer ratios of $1: 3\left(52.747 \pm 1.313^{q}\right)$ and 1:5 $\left(19.680 \pm 3.274^{\mathrm{q}}\right)$. However, there was no significant difference in protein concentrations between the buffer ratios of $1: 3$ and 1.5. In addition, in RIPA+Pi buffer, protein concentration in the buffer ratio of 1:1 $\left(106.747 \pm 12.616^{x}\right)$ was significantly higher $(\mathrm{p}<0.05)$ compared to that in the buffer ratio of $1: 5\left(36.213 \pm 1.733^{y}\right)$. However, protein concentration in the buffer ratio of 1:3 $\left(67.280 \pm 13.547^{x y}\right)$ was not significantly different from those in the buffer ratios of 1:1 and 1:5.

\section{Buffer Ratio}

The protein concentrations based on the types of buffer in buffer ratios of 1:1, 1:3, and 1:5 are presented in Figure 3 . The results showed that there were significant differences in protein concentrations $(p<0.5)$ among

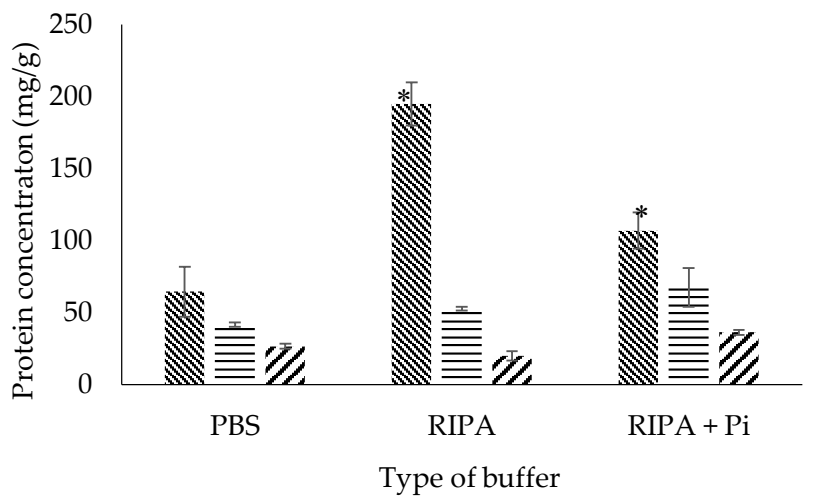

Figure 2. Protein concentrations for the buffer ratios of $1: 1(\mathbb{N})$, 1:3 (三), and 1:5 (/) in different types of buffers, phosphate buffer saline (PBS), radioimmunoprecipitation assay (RIPA), and RIPA + protease inhibitor (Pi). *Indicates the most significant among three ratios. the types of buffer in buffer ratios of 1:1 and 1:5. In contrast, there was no significant difference in protein concentrations among buffer types in the buffer ratio of 1:3. Post hoc test was conducted separately on the buffer ratios of $1: 1$ and $1: 5$. In the buffer ratio of 1:1, PBS $\left(64.347 \pm 17.458^{\mathrm{b}}\right)$ buffer and RIPA+ Pi $\left(106.747 \pm 12.616^{\mathrm{b}}\right)$ buffer did not show a significant difference in protein concentrations. However, protein concentration in RIPA buffer $\left(194.880 \pm 15.089^{a}\right)$ was significantly higher compared to those in PBS buffer and RIPA+Pi buffer. In the buffer ratio of $1: 5$, the mean protein concentration in PBS buffer $\left(26.480 \pm 1.744^{x y}\right)$ did not significantly different compared to that in RIPA + Pi buffer $\left(36.213 \pm 1.733^{y}\right)$. However, protein concentration in RIPA+Pi buffer was statistically higher $(p<0.05)$ compared to that in RIPA buffer $\left(19.680 \pm 3.274^{x}\right)$.

\section{Interaction between Buffer Type and Buffer Ratio}

There was a significant interaction $(\mathrm{p}=0.000, \mathrm{p}<0.05)$ between the type of buffer and buffer ratio on protein concentration. A test of simple effect was conducted and found that there were significant differences $(p=0.000$, $\mathrm{p}<0.05)$ among the average protein concentrations in the buffer ratio of 1:1 in various types of buffer, while no significant difference was detected in protein concentrations in the buffer ratios of $1: 3(p=0.210, p>0.05)$ and $1: 5(p=0.509, p>0.05)$ in various types of buffer. Based on the pairwise comparison table in the buffer ratio of $1: 1$, the results clearly showed that PBS, RIPA, and RIPA+Pi buffers were significantly different from each other. In term of the effects of buffer ratio of each type of buffer on protein concentration, it was clear that all buffer ratios of each buffer type had significant effects $(p<0.05)$ on protein concentration. Based on the pairwise comparison, it was clear that in PBS buffer, only buffer ratio of $1: 1$ that had protein concentration that significantly different from buffer ratio of 1:5. In RIPA buffer and RIPA+Pi buffer, there were significant differences in protein concentrations when compared between buffer ratio of $1: 1$ with buffer ratios of 1:3 and 1:5.

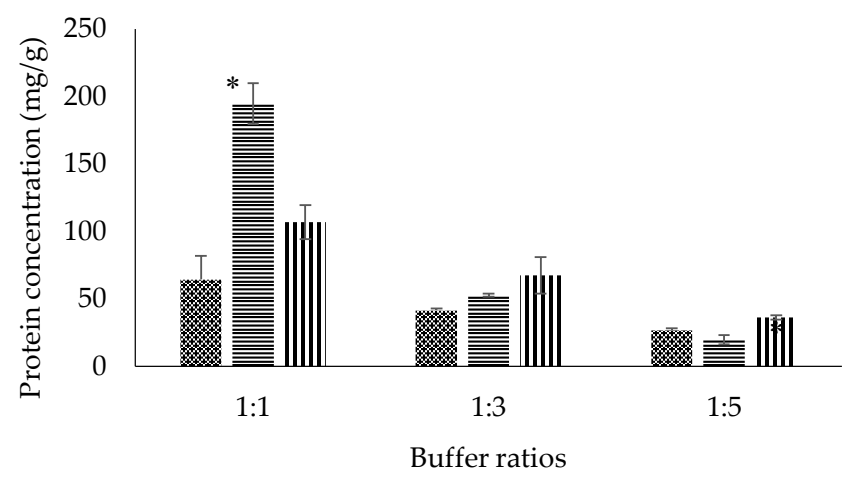

Figure 3. Protein concentrations based on the types of buffer (phosphate buffer saline (PBS, radioimmunoprecipitation assay (RIPA, 豆), and RIPA + protease inhibitor (Pi) (III) in different buffer ratios of 1:1, 1:3, and 1:5. *Indicates the most significant value among buffers. 


\section{DISCUSSION}

The protein yield is highly affected by the type of buffer $(p<0.05)$ (Figure 2$)$. The overall total protein concentration was relatively higher in RIPA buffer compared with PBS buffer while it was not significantly different compared with RIPA+ Pi buffer. These different effects of buffer types probably due to the different compositions of buffers used that significantly resulted in different cell disruptions which caused the different releases of protein from the cell compartment. RIPA buffer is one of the famous buffer as a choice for protein extraction from mammalian tissue (Kurien \& Hal Scofield, 2015). The significant increase in protein yield obtained could be the resulted of the presences of Triton X-100, sodium deoxycholate, and sodium dodecyl sulphate as detergents to solubilize the poorly soluble protein and break up the membrane structure of the cell. Hence, this condition allows the efficient rupture of the trophoblastic cell and the release of protein from the cell compartment. SDS and sodium deoxycholate are ionic detergents containing anionic hydrophilic head group possessing harsh properties that tend to denature protein as they disrupt both inter and intra molecular protein-protein interactions (Cockley, 2007). The presence of this detergent in buffer in protein extraction might cause a massive protein denaturation and reduce protein yield due to the above-mentioned properties, however, the total protein yield was relatively the highest among the three buffers. This difference probably due to the addition of Triton X-100 in the buffer, which relatively mild compared to SDS. Triton X-100 characterized as uncharged hydrophilic head groups, is a non-denaturing agent because it disrupts protein-lipid and lipid-lipid interactions instead of protein-protein interaction. Therefore, this detergent can help maintaining the stability of enzyme and efficiently solubilize the protein. However, the disruption of cell can be effectively undergone with the presence of these two detergents in disruption of interaction. Study conducted on membrane protein extraction, turned out the presence of SDS given out the highest total protein yield compared with non-ionic and zwitterionic detergent (Arachea et al., 2012). The addition of EDTA in the buffer act as a chelator helps to reduce oxidation damage of protein, particularly by metallo-protease through the formation of a stable complex with an enzyme complex (Auld, 1995).

Compared with PBS buffer, the lack of detergent and chelator in this buffer causes the disruptions of cells have to depend solely on the mechanical disruption to break the cell membrane for the release of protein. In addition to this point, the absence of a protease inhibitor causes the proteins were vulnerable to the protein degradation followed by the release of enzyme from the cell compartment after cell disruption. Hence, the low total protein could be due to the degradation of protein by the activation of enzyme (Fu et al., 2014). Phosphate and Tris- $\mathrm{HCl}$ act as buffering agents preventing protein denaturation by protecting protein from a huge fluctuation of the $\mathrm{pH}$ after the releases of substances during cell disruption. There should be no difference of impact on total protein yield between the choice of either phosphate or Tris- $\mathrm{HCl}$ as suggested by Sepehrimanesh (2015) that there was no significant difference between the choice of phosphate and Tris- $\mathrm{HCl}$ on protein concentration (El Amiri et al., 2015; Sepehrimanesh \& Kazemipour, 2015).

Hypothetically, the total protein yield of the RIPA+Pi buffer should relatively higher than RIPA without protease inhibitor since protease inhibitors function to protect the protein samples from being degraded by the protease liberated from the membrane fragment and cellular compartment (G-Biosciences, 2012 $\&$ 2018). However, the current experiment gives a negative outcome where there is no significant difference between protein yields between RIPA with protease inhibitor and RIPA without protease inhibitor. This nonsignificant difference could be related to the poor handling causing the inactivation of protease inhibitor solution as protease inhibitors are unstable for long duration of time, either in stock solution or working concentration (Ritchie, 2013). The mishandling could be happened from the beginning in making of protease inhibitor, or contamination occurred during the process of transferring part of stock solution into the unsterilized container. Inactivation of protease inhibitor could be happened due to the inappropriate storage problem as protease inhibitors are sensitive to fluctuation of temperature. The allocated incubation time for RIPA+Pi buffer can be one of the possible reasons for the lower protein yield compared to the RIPA buffer, due to the incomplete protein solubilization compared to the RIPA buffer alone.

Pregnancy-specific protein B is a type of glycoprotein and also belongs to aspartic enzyme family (Klisch et al., 2006). Protease inhibitor cocktail containing variety types of inhibitors including aspartic protease inhibitor such as pepstatin, acts as a reversible protease inhibitor. This condition resulted in the binding of aforementioned targeted protein and causes the protein failed to form dye-protein complex with Coomassie Brilliant Blue in Bradford assay causing an erroneous in data collection.

Currently, there are limited studies related to the optimization of buffer ratio in protein extraction. Theoretically, the buffer ratio of 1:3 can produce more concentrated extract while the volumes of 5 to 10 of buffer are able to yield more soluble protein and less viscous extract (Grabski, 2009). Study conducted on protein extraction on banana reported that the buffer ratio of 1:3 could yield protein compared with the buffer ratios of 1:1 and 1:5 (Mayil Vaganan et al., 2015). This statement was partially proven by the current experimental data where the total protein concentration in the buffer ratio of $1: 3$ were significantly higher than in buffer ratio of $1: 5$ $(p<0.05)$ but were lower than in the buffer ratio of 1:1. While the statement of ratio of sample to buffer at the ratio of 1:5 was found to be optimal in protein extraction of monoclonal antibodies (Gottschalk, 2014), this result seems contradictive with the result of this experiment. Geissler et al. (2011) agree that the ratio of $5 \mathrm{~mL}$ buffer per gram can be the starting point to avoid the loss of protein activity or nonspecific binding to containers. However, then again, the ratio of buffer has to be lower 
down, such as 1:1 or 1:2, if concentrated sample is essential. Golemis \& Adams (2005) suggested that unnecessary dilution of cells in lysis buffer should be avoided as this might causes the instability in structure and activity, therefore the buffer ratio of 1:1 was supported. Based on the data result, the buffer ration of 1:1 was apparently the highest among the three ratios, proven that more protein solubilized in compared with the other ratios.

The low protein yield in the buffer ratios of $1: 3$ and 1:5 could be due to the excessive contents within each lysis buffer that caused protein denaturation. The denatured protein aggregated and formed layer at the bottom of the tube after centrifugation. In RIPA buffer, the increase in buffer to sample ratio implied the increase in detergent level compared to protein level within the sample. Supposedly, the increase in non-ionic Triton-X 100 detergent level could aid the solubilization of protein which can improve the protein yield by disruption of membrane protein through detergent-lipid interaction. However, the increase in SDS and sodium dodecyl cholate as ionic detergent has disrupted the protein-protein interactions, and converts protein into the denatured state (Stetsenko \& Guskov, 2017).

The presence of salt helps in maintaining the ionic strength of the medium, and increases the total concentration of solutes outside the cell (Brennan, 2018). In PBS buffer, the total protein yield decreased with the increased ratio of buffer to sample that possibly related to the raising of salt concentration in the tissue surrounding that eventually inactivated some of the proteins (Chandra \& Endow, 1993). In term of RIPA buffer added with protease inhibitor, the increased amount of protease inhibitor followed by the increased of buffer to sample ratio resulted in a greater formation of protease inhibitor-protein complex causing a poor yield of protein. Some protease inhibitor may carry out irreversible function which causes denaturation of the protein and eventually decreases the result of total protein yield.

There was no significant difference in total protein yield ( $p=0.147, p>0.05$ ) among three buffers in the ratio of 1:3 suggesting either of these three buffers can be used in the ration of $1: 3$ and will not bring a huge difference in term of total protein yield.

In the buffer ratio of 1:5, RIPA+Pi buffer produced a statistically a higher protein yield compared to RIPA and PBS buffers, which suggested that RIPA+Pi buffer could yield better proteins in the buffer ratios of $1: 3$ and 1:5 compared with the other types of buffers with the same ratio. This condition may possibly because of too much detergent within the RIPA buffer that causes denaturation of the protein and results in low total protein yield. Incomplete protein solubilization may happen in PBS buffer due to the lack of additive except salt, and this condition causes the result that the cell disruption had to depends on the mechanical force to break the cell membrane. Additionally, this condition may contribute to the incomplete disruption of cell membrane in PBS buffer and the proteins were remained in the cellular compartment.

In the comparison with the result of previous study, it was found out that the current study has greatly enhanced the total protein yield whereby the to- tal protein yield in several present researches related to the extraction of placental protein could yield about 13 to $16 \mathrm{mg} / \mathrm{g}$ of total protein from either bovine or ovine (Arima \& Bremel, 1983; Azadmanesh et al., 2012; Barbato et al., 2013). However, the protein centration obtained from Bos taurus species during late pregnancy (270 days of pregnancy) is approximately $618.8 \pm 17.1 \mathrm{mg} / \mathrm{g}$ (Sharpe et al., 1989) much higher compare to Bos indicus used in this study. In addition, the content of PAG presented could not be compared with previous study due to the detection of PAG was not conducted in this study.

\section{CONCLUSION}

The yield of protein concentration from radioimmunoprecipitation assay (RIPA) buffer gives out the highest protein concentration among three buffers due to the presence of detergent that improves the solubilization of protein. However, the incubation time and the presence of aspartic protease from protease inhibitor has inhibited the binding of the desired proteins. The buffer ratio of 1:1 produces the best result due to the increase of content level to tissue causes the denaturation of protein.

\section{CONFLICT OF INTEREST}

We certify that there is no conflict of interest with any financial, personal, or other relationships with other people or organization related to the material discussed in the manuscript.

\section{ACKNOWLEDGEMENT}

This research was fully funded by the Ministry of Higher Education, Malaysia under the FRGS grant scheme (R/FRGS/A07.00/00130A/002/2017/000437). Our deepest gratitude to the Dean of Faculty of Agro Based Industry, Universiti Malaysia Kelantan for allowing us to use the laboratories and all of the equipment.

\section{REFERENCES}

Abdulkareem, T. A., S. A. M. Al-Sharifi, M. A. Ishak, S. M. Eidan, M. A. Alnimr, C. W. Passavant, J. R. Branen, \& R. G. Sasser. 2011. Early pregnancy detection of Iraqi Riverine Buffalo (Bubalus bubalis) using the BioPRYN enzyme-linked immunosorbent assay for PSPB and the progesterone assay. Reprod. Dom. Anim. 46: 455-462. https:// doi.org/10.1111/j.1439-0531.2010.01689.x

Arachea, B. T., Z. Sun, N. Potente, R. Malik, D. Isailovic, \& R. E. Viola. 2012. Detergent selection for enhanced extraction of membrane proteins. Protein Expression and Purification 86: 12-20. https://doi.org/10.1016/j.pep.2012.08.016

Arima, Y. \& R. D. Bremel. 1983. Purification and characterization of bovine placental lactogen. Endocrinology 113: 21862194. https://doi.org/10.1210/endo-113-6-2186

Auld, D. S. 1995. Removal and replacement of metal ions in metallopeptidases. Methods in Enzymology 248: 228-242. https://doi.org/10.1016/0076-6879(95)48016-1

Azadmanesh, K., Z. S. Norouzfa, A. Sohrabi, Z. Safaie-Naraghi, A. Moradi, P. Yaghmaei, M. M. Naraghi, A. Arashkia, \& A. Eslamifar. 2012. Characterization of human herpes virus 8 genotypes in kaposi's sarcoma patients in Tehran, 
Iran. International Journal of Molecular Epidemiology and Genetics 3: 144-152.

Barbato, O., N. Melo de Sousa, V. L. Barile, C. Canali, \& J-F. Beckers. 2013. Purification of pregnancy-associated glycoproteins from late-pregnancy Bubalus bubalis placentas and development of a radioimmunoassay for pregnancy diagnosis in water buffalo females. BMC Veterinary Research 9: 89. https://doi.org/10.1186/1746-6148-9-89

Beriot, M., A. F. Tchimbou, O. Barbato, J-F. Beckers, \& N. M. de Sousa. 2014. Identification of pregnancy-associated glycoproteins and a-fetoprotein in fallow deer (Dama dama) placenta. Acta Veterinaria Scandinavica 4: 56. https://doi. org/10.1186/1751-0147-56-4

Brennan, J. 2018. Components of Lysis Buffers | Sciencing. https://sciencing.com/components-lysis-buffers-8148370. html. [9 December 2018]

Chaves, C. D. M. E. S., R. L. Dias da Costa , K. M. R. Duarte , D.C. Machado , C. C. Paro de Paz, \& R. T. Beltrame. 2017. Visual ELISA for detection of pregnancy-associated glycoproteins (PAGs) in ewe serum. Theriogenology 97: 78-82. https://doi.org/10.1016/j.theriogenology.2017.04.026

Chandra, R. \& S. A. Endow. 1993. Microtubule Motor Protein Expression in Bacteria. In: J. M. Scholey (Ed.), Motility Assays for Motor Proteins. Academic Press Inc, San Diego, California. p. 119-122.

El Amiri, B., N. M. Sousa, A. A. Oxiley, D. Hadarbach, \& J-F. Beckers. 2015. Pregnancy-asso- ciated glycoprotein (PAG) concentration in plasma and milk samples for early pregnancy diagnosis in Lacaune dairy sheep. Res. Vet. Sci. 99: 30-36. https://doi.org/10.1016/j.rvsc.2014.12.016

Friedrich, M. \& W. Holtz. 2010. Establishment of an ELISA for measuring bovine pregnancy-associated glycoprotein in serum or milk and its application for early pregnancy detection. Reprod. Dom. Anim. 45:142-146. https://doi. org/10.1111/j.1439-0531.2008.01287.x

Fu, Q., J. Cheng, Y. Gao,Y. Zhang, X. Chen, \& J. Xie. 2015. Protease- activated receptor 4: a critical participator in inflammatory response. Inflammation 38: 886-895. https:// doi.org/10.1007/s10753-014-9999-6

G-Biosciences. 2012. What are Protease Inhibitors and How Do They Work?. https://info.gbiosciences.com/blog/ bid/160009/what-are-protease-inhibitors-and-how-dothey-work. [9 December 2018]

G-Biosciences. 2018. Protease and Phosphatase Inhibitors, Enzymes and Assays Handbook and Selection Guide. G-Biosciences.

Geissler, M., J. A. Beauregard, I. Charlebois, S. Isabel, F. Normandin, B. Voisin, M. Boissinot, M. G. Bergeron, \& T. Veres. 2011. Extraction of nucleic acids from bacterial spores using bead-based mechanical lysis on a plastic chip. Engineering in Life Sciences 11: 174-181. https://doi. org/10.1002/elsc.201000132

Golemis, E. \& P. D. Adam. 2005. Protein-Protein Interactions: A Molecular Cloning Manual (Second). CHSL Press, Philadelphia, Pennsylvania.

Gottschalk, U. 2014. Process Scale Purification of Antibodies. $2^{\text {nd }}$ Ed. John Wiley \& Sons, Inc.

Grabski, A. C. 2009. Chapter 18 advances in preparation of biological extracts for protein purification. Methods in Enzymology 463: 285-303. https://doi.org/10.1016/ S0076-6879(09)63018-4

Helmenstine, A. M. 2018. Glycoprotein Definition and Function. https://www.thoughtco.com/glycoprotein-definition-andfunction-4134331 [10 November 2018]
Klisch, K., A. Boos, M. Friedrich, K. Herzog, M. Feldmann, N. M. Sousa, J-F. Beckers, R. Leiser, \& G. Schuler. 2006. The glycosylation of pregnancy-associated glycoproteins and prolactin-related protein-I in bovine binucleate trophoblast giant cells changes before parturition. Reproduction. 132: 791-798. https://doi.org/10.1530/REP-06-0040

Kurien, B. T. \& R. H. Scofield. 2015. Western blotting: Methods and protocols. 1312: 17-30. https://doi. org/10.1007/978-1-4939-2694-7

Majewska, M., G. Panasiewicz, \& B. Szafranska. 2011 Pregnancy-associated glycoprotein (PAG) family localized in chorionic cells within the epitheliochorial/diffuse placenta of the alpaca (Lama pacos). Acta Histochemica. 113: 570-577. https://doi.org/10.1016/j.acthis.2010.06.002

Piechotta, M., J. Bollwein, M. Friedrich, T. Heilkenbrinker, C. Passavant, J. Branen, G. Sasser, M. Hoedmaker, \& H. Bollwein. 2011. Comparison of commercial ELISA blood test s for early pregnancy detection in dairy cows. J. Reprod. Dev. 57:72-75. https://doi.org/10.1262/jrd.10-022T

Ritchie, C. 2013. Protease Inhibitors: Materials and Methods. Labome. 3: 169. https://doi.org/10.13070/mm.en.3.169

Romano, J. E. \& J. E. Larson. 2010. Accuracy of pregnancy specific protein-B test for early pregnancy diagnosis in dairy cattle. Theriogenology 74: 932-939. https://doi. org/10.1016/j.theriogenology.2010.04.018

Sepehrimanesh, M., \& N. Kazemipour. 2015. Relationship between the types of the extraction buffer with quality of the 2-dimensional electrophoresis proteomic map. Journal of Cytology and Molecular Biology 2: 2-4.

Sharpe-Timms, K. L., H. Eiler, W. C. Cullen, F. M. Hopkins. 1989. Morphometric analysis of collagen in gestational and retained bovine placentomes. Theriogenology 32: 485-491. https://doi.org/10.1016/0093-691X(89)90015-0

Stetsenko, A., \& A. Guskov. 2017. An overview of the top ten detergents used for membrane protein crystallization. Crystals 7: 197. https://doi.org/10.3390/cryst7070197

Takahashi, T., K. Hayashi, \& M. Hosoe. 2013. Biology of the placental proteins in domestic ruminants: expression, proposed roles and practical applications. Japan Agric. Res. Quat. 47:43-51. https://doi.org/10.6090/jarq.47.43

Telugu, B. P., M. O. Palmier MO, S. R. Van Doren, \& J. A. Green. 2010. An examination of the proteolytic activity for bovine pregnancy-associated glycoproteins 2 and 12 . Biological Chemistry 391: 259-270. https://doi.org/10.1515/ bc

Touzard, E., P. Reinaud, O. Dubois, C. Guyader-Joly, P. Humblot, C. Ponsart \& G. Charpigny. 2013. Specific expression patterns and cell distribution of ancient and modern PAG in bovine placenta during pregnancy. Reproduction 146: 347-362. https://doi.org/10.1530/ REP-13-0143

Vaganan, M. M., S. Sarumathi, A. Nandakumar, I. Ravi, \& M. M. Mustaffa. 2015. Evaluation of different protein extraction methods for banana (Musa spp.) root proteome analysis by two-dimensional electrophoresis. Indian Journal of Biochemistry and Biophysics 52: 101-106.

Wallace, R. M., K. G. Pohler, M. F. Smith, \& J. A. Green. 2015. Placental PAGs: gene origins, expression patterns, and use as markers of pregnancy. Reproduction 149: 115-126. https://doi.org/10.1530/REP-14-0485

Zhao, P., M. Metcalf, \& N. W. Bunnett. 2014. Biased signaling of protease- activated receptors. Frontiers in Endocrinology 5: 67. https://doi.org/10.3389/fendo.2014.00067 